\title{
The Self-thinking Supply Chain
}

\begin{abstract}
Purpose: An emerging theme in the practitioner literature suggests that the supply chain of the future enabled especially by developments in ICT - will be autonomous and have predictive capabilities, bringing significant efficiency gains in an increasingly complex and uncertain environment. This paper endeavours to both (i) bridge the gap between the practitioner and academic literature on these topics and (ii) contribute to both practice and theory by seeking to understand how such developments will help to address key supply chain challenges and opportunities.
\end{abstract}

Design/methodology/approach: A multi-disciplinary, systematic literature review was conducted on relevant concepts and capabilities. A total of 126 articles were reviewed covering the time period 19502018.

Findings: Results show that both IoT and AI are the technologies most frequently associated with the anticipated autonomous and predictive capabilities of future supply chains. In addition, the review highlights a lacuna in how such technologies and capabilities help address key supply chain challenges and opportunities. A new supply chain model is thus proposed, one with autonomous and predictive capabilities: the self-thinking supply chain.

Originality/value: It is our hope that this novel concept, presented here for the first time in the academic literature, will help both practitioners to craft appropriate future-proofed supply chain strategies and provide the research community with a model (built upon multidisciplinary insights) for elucidating the application of new digital technologies in the supply chain of the future. The self-thinking supply chain has the potential in particular to help address some of today's key supply chain challenges and opportunities.

Keywords: self-thinking supply chain, Internet of Things, artificial intelligence, autonomous, predictive.

Paper type: Research paper.

\section{Introduction}

A large number of academic and practitioner publications have acknowledged that supply chain management is undergoing significant changes due to the adoption of new digital technologies (Capgemini, 2016; DHL, 2016; Wu et al., 2016; Haddud et al., 2017). Breakthroughs in several fields, such as the Internet of Things (IoT), artificial intelligence (AI), robotics, autonomous vehicles, and additive manufacturing are transforming all the steps in supply chain management (WEF, 2017). This is taking place in the context of the Fourth Industrial Revolution, a revolution that is characterized by an unprecedented advance in digital technology, and which is blurring the lines between the physical, digital, and biological spheres (Schwab, 2016). Among the breakthroughs that characterize the Fourth Industrial Revolution is the ability to collect and analyse massive amounts of data in an automated way, then use this data for decision making and implement decisions in real time. Practitioner research suggests that there will be more than 50 billion devices connected to the Internet by 2020 (Cisco, 2011), a trillion sensors connected to and transmitting information to analytical platforms in the cloud, and 44 trillion gigabytes generated (DHL, 2015). In this context, information that was previously created by people will 
increasingly be machine-generated, while the entire supply chain will be connected, including parts, products, and other smart objects used to monitor the supply chain (IBM, 2015). Based on these data, supply chains will be able to make decisions more accurately and in real time, to optimize operations, handle incidents that require risk-mitigation actions, avoid disruptions, and satisfy an increasingly volatile demand (Calatayud, 2017).

Notably, many commentators argue that the supply chain of the future will be autonomous and have predictive capabilities (IBM, 2015; DHL, 2016; WEF, 2017). This, they say, will bring significant performance improvement in an increasingly complex and uncertain environment for supply chain management. Indeed, supply chains currently face a variety of risks due to growing internationalization and firm interconnection, higher demand volatility, and faster supply chain speed (Christopher and Holweg, 2011 and 2017). Driven by new digital technologies, the supply chain of the future will increasingly be self-aware, think by itself and require minimum, if any, human intervention to manage risks. The self-thinking supply chain will continuously monitor supply chain performance by analysing quintillion bytes of data generated by objects; forecast and identify risks; and automatically take actions to prevent risks before they materialize. The supply chain will autonomously learn from these activities and use such knowledge in future decisions. Importantly, large amounts of data and the use of powerful analytical and simulation models will allow the supply chain to predict the future with minimum error and take actions to, for example, address constant shifts in demand. The self-thinking supply chain will thus push supply chain flexibility and agility to limits yet to be discovered (Calatayud, 2017).

Despite these promising benefits for supply chain management (SCM), literature on self-thinking supply chain is scarce. The term is mentioned only infrequently in the practitioner literature in an attempt to predict future SCM trends with the simultaneous adoption of different new digital technologies (DHL, 2016; Calatayud, 2017; IBM, 2017). In the academic literature, however, current research mainly focuses on identifying the impact of a single new digital technology - such as IoT - on supply chain performance. Therefore, in this paper we seek to understand, from both practical and theoretical perspectives, how multiple digital technologies will shape future supply chains. The literature on automated, predictive and self-thinking supply chains, and related concepts and capabilities, is reviewed. The insights from that review are then considered in the context of the current understanding of supply chain strategy and a new supply chain model - the self-thinking supply chain - is posited. The systematic literature review spans disciplines such as Supply Chain Management, Computer Science, Engineering, and Economics. It is our hope that this novel concept, described here for the first time in the academic literature, will help both practitioners to craft appropriate future-proofed supply chain strategies and provide the research community with a model (built upon multidisciplinary insights) for elucidating the application of new digital technologies in the supply chain of the future.

This paper is organized as follows: Section 2 lays out the methodology and procedures followed to conduct the systematic literature review; Section 3 presents the results of the systematic literature review; Section 4 discusses the impact of new digital technologies on SCM according to the extant literature; Section 5 introduces the self-thinking supply chain model and elucidates its contribution to supply chain strategy; and Section 6 presents the conclusions and outlines areas for future research.

\section{Methodology}

In order to explore the characteristics of a self-thinking supply chain, the systematic literature review technique was applied. This technique uses systematic methods to identify, select and critically evaluate the body of knowledge related to a given topic (Gligor and Holcomb, 2012; Rousseau et al., 2008; Tranfield et al., 2003). Unlike a traditional literature review, which might be influenced by the familiarity or preferences of the reviewer, a systematic literature review allows the researcher to gather, analyse and 
interpret a comprehensive body of available literature in a thorough and unbiased manner (Wang and Notteboom, 2014).

The systematic review technique is particularly relevant to the purpose of this paper. By avoiding the biases of conventional literature reviews, a systematic review allows the researcher to: (1) summarize the accumulated body of knowledge related to the topic of interest; (2) explore the topic through different perspectives; and (3) develop reliable knowledge from a pool of knowledge dispersed across a broad range of studies (Gligor and Holcomb, 2012; Tranfield et al., 2003). Given that the pool of knowledge on new digital technologies and supply chain management is spread across a variety of academic disciplines and that, according to practitioner literature, a self-thinking supply chain encompasses the use of different technologies, the systematic literature review is deemed appropriate to explore how multiple digital technologies will shape future supply chains. Indeed, a systematic review of automated, predictive and self-thinking supply chains, and related concepts and capabilities allows us to explore available academic literature comprehensively, giving insights on the meaning, enablers and potential benefits of a selfthinking supply chain, while bridging the gaps among different perspectives and developing a broad understanding of the research topic.

Applying the systematic review technique involves five stages (Figure 1): (1) problem formulation; (2) literature research; (3) selection and evaluation of literature; (4) research analysis and interpretation; and (5) presentation of results (Denyer and Tranfield, 2009; Gligor and Holcomb, 2012). The problem addressed in this paper was formulated as follows: given that the pool of knowledge on new digital technologies and supply chain management is spread across a variety of academic disciplines, can we aim to develop an integrated framework to understand the defining aspects of a self-thinking supply chain and its potential benefits from both practical and theoretical perspectives. The literature was researched by interrogating the dataset Scopus, one of the largest repositories of academic articles. Literature research comprised five stages. In the first stage, keyword search was performed using the words ("self-thinking") AND ("supply chain"), together with related words such as ("autonomous" OR "predictive") AND ("supply chain"), in papers and conference proceedings published between 1950 - the earliest available year in the dataset - and February 2018. In the second stage, studies were chosen and evaluated according to a set of specific criteria that referred to: (1) the relevance of the study to the research problem; and (2) the quality of the study. In agreement with Wang and Notteboom (2014), the Critical Appraisal Skills Program (CASP) checklist was used to evaluate the quality of the studies. Studies selected in stage two were analysed in order to identify shared patterns among them. The analysis showed that studies could be grouped into two domains: (1) studies exploring the use of Internet of Things (IoT) in SCM; and (2) studies exploring the use of artificial intelligence (AI) in SCM. In the third stage, the dataset was further interrogated using keywords that referred to such domains. In the fourth stage, search results were evaluated according to the relevance and quality criteria applied in stage two. References included in the papers collected were used as guidance for further exploration of the literature. In addition, literature citing the papers collected were identified and analysed. In all queries, words closely related to self-thinking such as 'smart' or 'intelligent' were considered as well. In the fifth stage, the review of articles was complemented by searching: (1) the catalogue of the United States Library of Congress (the biggest library catalogue in the world) for books that could be related to the topic; and (2) Google search engine, using the same keywords that were used in the Scopus query, to account for working papers and reports relevant to the topic published by other sources, such as national and international organizations. Search results were evaluated according to the relevance and quality criteria applied in stage two. 


\section{Results}

The first stage of the literature research resulted in 89 articles. In stage two, the 89 articles were evaluated according to the relevance and quality criteria, with 28 articles satisfying such criteria (Table 1). Next, the articles selected were preliminarily analysed with the objective of identifying shared characteristics that could be used to group and classify them into different categories. The analysis showed that articles could be classified into two broad domains: (1) articles exploring the use of IoT in SCM, including studies with a focus on planning and management of activities that integrate supply and demand within and across companies; (2) articles exploring the use of AI in SCM, including studies that develop and apply different types of algorithms to dynamically solve supply chain optimization problems. These categories were then used to further query the database, looking for articles relevant to the research problem.

\section{[Table 1]}

In the third stage, the database was interrogated by searching for words related to the two domains identified in the previous phase: IoT and AI. The words ("Internet of Things" OR "IoT") AND ("supply chain") were searched for the first domain, resulting in 397 articles, among which 56 articles satisfied the relevance and quality criteria. Next, the words ("artificial intelligence" OR "machine learning") AND ("supply chain") were selected for the second domain, resulting in 141 articles, among which 23 articles satisfied the selected criteria. In addition, a third search was performed using the keywords ("Internet of Things" OR "IoT") AND ("artificial intelligence" OR "machine learning") AND ("supply chain") to identify articles encompassing both types of technology, thus combining both domains. This search resulted in 22 articles, among which 17 articles satisfied the selected criteria. Overall, after applying the relevance and quality criteria to the results, 68 articles were selected, making up the basis for further analysis. The earliest article included in the dataset had been published in 2007 and the most recent in 2018. This time period is consistent with the exponential growth of academic interest in the subject of digital technologies applied to SCM. Indeed, the simple search for the keywords ("digital") AND ("supply chain") on Scopus showed that $80 \%$ of the academic publications found (1,128 articles) were published in the period 2007-2018. In addition to the articles selected for analysis, both references contained in and literature citing these articles were analysed and also included when they satisfied the selected criteria.

In the fifth stage, the literature research was complemented by querying the catalogue of the United States Library of Congress and Google search engine, using the same keywords from previous phases. Arising from the five stages of the literature research, 126 studies were selected and analysed (Figure 1). 
Figure 1. Graphical illustration of the literature search process and results

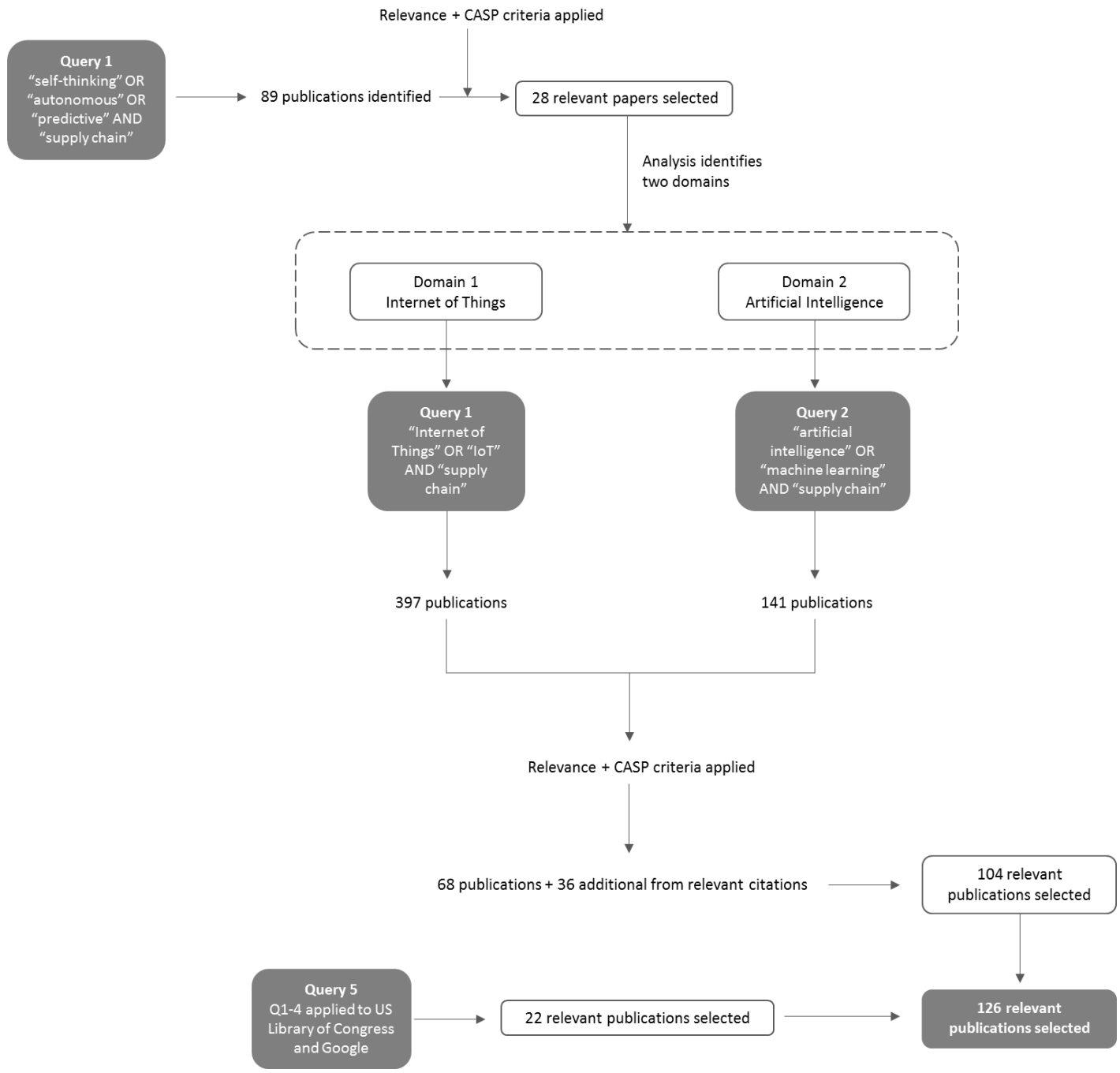

Table 2 shows the five journals with the highest number of articles selected through the literature search process.

[Table 2]

\section{IoT, Artificial Intelligence and SCM}

SCM aims to get, in the right way, the right product, in the right quantity and right quality, in the right place at the right time, for the right customer at the right cost (Mangan and Lalwani, 2016). However, growing supply chain complexity, higher demand volatility, unprecedented technological changes, and supply chain speed are making SCM increasingly challenging (Christopher and Holweg, 2017; Fore et al., 2017). In $201732 \%$ of S\&P 500 companies were affected by supply chain disruptions (Resilinc, 2018). To overcome supply chain risks and vulnerabilities, academic and practitioner literature suggests that 
smarter supply chains must be built (Butner, 2010). These supply chains will use a range of technologies to respond to changing environments, with or without human intervention (Wu et al., 2016). Therefore, available literature anticipates that a revolution on how supply chains work and are managed lies ahead (Zjim and Klumpp, 2015).

Practitioner research argues that, in the future, supply chains will be autonomous and will have predictive capabilities (IBM, 2015; DHL, 2016; WEF, 2017). Using IoT sensors, quintillion bytes of data will be generated across supply chain operations. AI will be deployed to analyse information in real time, monitor operations across the globe, predict the future with minimum error rate, and take actions to adjust to rapidly changing environments (DHL, 2016). Such supply chains will be self-thinking, requiring minimum, if any, human intervention (Calatayud, 2017). In spite of the promising benefits of the selfthinking supply chain found in practitioner literature, academic research on this and related topics is scarce. Our systematic literature review found no articles exploring the self-thinking supply chain and only 28 articles referring to related concepts such as 'autonomous', 'predictive', 'smart' or 'intelligent' supply chain. These articles are spread across different fields, including Supply Chain Management, Computer Science, Engineering, and Economics. The analysis of the selected articles gave insights into in particular two new digital technologies that are associated with autonomous, predictive, smart or intelligent supply chains, namely: Internet of Things (IoT) and artificial intelligence (AI). As shown in Table 1, half of the initial 28 articles retrieved referred to the use of IoT to improve SCM. In turn, nine articles discussed the application of AI in SCM. Finally, five articles explored the benefits of both IoT and AI for SCM. The sub-sections that follow analyse both technologies according to the 126 publications retrieved in the systematic literature review. Table 3 provides a summary of our findings and categorises the main research related to the topic under examination.

[Table 3]

\subsection{Internet of Things and SCM}

The systematic literature review revealed that academic interest on IoT and SCM is fairly recent. Indeed, the oldest article in our dataset was published in 2004. That article analysed the promises of applying RFID technology for SCM and suggested that the ultimate goal was "to create an 'Internet of things' in which everyday physical items are networked together" (Luckett, 2004, p. 50). More recently, interest in IoT and SCM has been increasing: 44\% of the 397 articles found in Scopus were published between 2016 and 2018. In 2017, Ben-Daya et al. published an article which analysed the literature on IoT and SCM. While those authors' work is certainly a good reference point for this paper, in our systematic literature review we retrieved additional work not included in Ben-Daya et al. (2017), particularly regarding the transmission mechanism by which IoT impacts on SCM, as well as the different technologies encompassed by IoT and the interaction of IoT with other new digital technologies. As mentioned before, literature is spread across different disciplines, with Computer Science (64\% of publications retrieved), Engineering (52\%), and Business and Management (24\%) being the fields with higher numbers of publications. In terms of the geographic areas of authors' affiliation, China (34\%), the United States (14\%), and the United Kingdom (8\%) are leading knowledge creation in this field. In the next subsections, the publications retrieved are analysed according to three aspects of IoT technology discussed in the literature: its definition, its enablers, and its impact on SCM.

\subsubsection{IoT definition}

A number of articles locate the beginning of IoT in the late 1990s, when the term was coined by Ashton to refer to uniquely identifiable objects (things) through RFID technology and their virtual representations in an internet-alike structure (Zhou et al., 2015; Papert and Pflaum, 2016; Rezaei et al., 2017). Since then, 
and particularly in the last three years, many IoT definitions have been suggested in the literature, some are more specific to the technologies encompassed by IoT, while others are more comprehensive and include the purpose of the technology (Haddud et al., 2017; Hofmann and Rusch, 2017). Regarding the former, most of the definitions retrieved in the literature search suggest that IoT technology refers to at least three elements: (i) technology for data collection; (ii) technology for data transmission; and (iii) technology for data analysis (Reaidy et al., 2015; Dweekat et al., 2017; Lu, 2017). According to Gnimpieba et al. (2015), the added value of IoT is precisely the integration of different layers of sensors, data transmission and storage, setting the data collected available to users. Likewise, Lu (2017) states that the IoT integrates various devices equipped with sensing, identification, processing, communication, and networking capabilities. Vermesan et al. (2011) and Reaidy et al. (2015) focus on the network characteristic of IoT, referring to it as a "dynamic global network infrastructure with self-configuring capabilities based on standard and interoperable communication protocols where physical and virtual 'things' have identities, physical attributes, and virtual personalities, use intelligent interfaces, and are seamlessly integrated into the information network" (Reaidy et al., 2015, p. 29).

Other IoT definitions are more comprehensive in the sense that they include the purpose of the technology. For example, Zhou et al. (2015) refer to IoT as a "devices or sensors connected world where objects are connected, monitored, and optimized through wired, wireless or hybrid systems" (Zhou et al., 2015, p. 1). Gnimpieba et al. (2015) state that IoT is an evolution in computer technology and communication that aims to connect objects together via the Internet. According to the authors, the flow of information and events generated by the interconnection of these objects is used to facilitate their tracking, management, control and coordination. Likewise, Yan (2017, p. 730) suggests that the IoT is "an internet-based intelligent network which is capable of transferring real-time information, as well as identifying, tracking and managing products through advanced technologies such as radio frequency identification (RFID), infrared sensor, global positioning system and laser scanner". Ben-Daya et al. (2017) go beyond the purpose of technology to include the expected impact of IoT on SCM. According to the authors, IoT is "a network of physical objects that are digitally connected to sense, monitor and interact within a company and between the company and its supply chain enabling agility, visibility, tracking and information sharing to facilitate timely planning, control and coordination of the supply chain processes" (Ben-Daya et al., 2017, p. 3).

\subsubsection{IoT enablers}

Part of the literature retrieved analyses the enablers of IoT. Similar to the case of IoT definition, some articles limit their focus to RFID technology, while others include a wide range of technologies that enable data collection, transmission, and processing. Literature on RFID technology is abundant, since this technology has been applied in the field of SCM for years (Sarac et al., 2010; Zhu et al., 2012). RFID is "a wireless communication technology that can identify specific targets using radio signals and read and write relevant data without mechanical or optical contact between the system and the target" (Yan et al., 2017, p. 2). According to Zhang et al. (2013), RFID is the key technology enabling IoT systems. The technology is based on an integrated circuit with an antenna or tag, which can store information. These tags can be placed on different objects along the supply chain to sense their properties. Some tags allow additional information to be written onto them as the tags pass through different parts of the supply chain (Lee and Ozer, 2007). Tag information is retrieved through readers and wireless technology. In contrast to barcodes, readers do not need contact or line of sight to retrieve tag information; hence, the location/orientation of the reader does not matter as long as the tags are within the range of the reader's signal (Delen et al., 2007). In turn, tags can be passive or active. While the former require no internal power and respond to signals emitted by the readers, the latter are self-powered and have the capacity to send out signals to readers, allowing them to be read faster, at greater distances and with less interference (Lee and Ozer, 2007; Yuvaraj and Sangeetha, 2016). 
Beyond RFID, Lu (2017) suggests that an IoT system consists of Industrial Wireless Networks (IWN), including machines and equipment, networks, the cloud, and terminals. Zhang et al. (2013) and Reaidy et al. (2015) mention as part of an IoT system technologies such as WiFi, Bluetooth, ZigBee, Embedded devices (RFID or wireless sensor networks) and applications. Dweekat et al. (2017) provides further insight into the technology encompassed by IoT, distinguishing four layers of technologies (Figure 2):

i. The sensing or perception layer, which consists of three components: (a) object identification properties, such as RFID tags, or any property of objects that can be sensed (e.g. shape, size, temperature, etc.); (b) reader tools and sensors; and (c) means to create short-area networks, such as Wi-Fi, ZigBee, etc.

ii. The gateway and network layer, whose role is to connect objects or things and allow them to share and exchange information. It contains a gateway, an internal network or a local area network (LAN) to connect this second layer (gateway) with the first one (sensing layer), and an external network or wide area network (WAN) to communicate with other networks.

iii. The management service layer, which relies on middleware technology that allows data storage and interaction among multiple devices and processes running on one or more machines. It is in charge of information analytics, security control, process modelling, and device management.

iv. The application layer, where collected and transmitted data are saved and processed through certain techniques, and objects or things are managed and controlled.

Figure 2. Supply chain IoT architecture

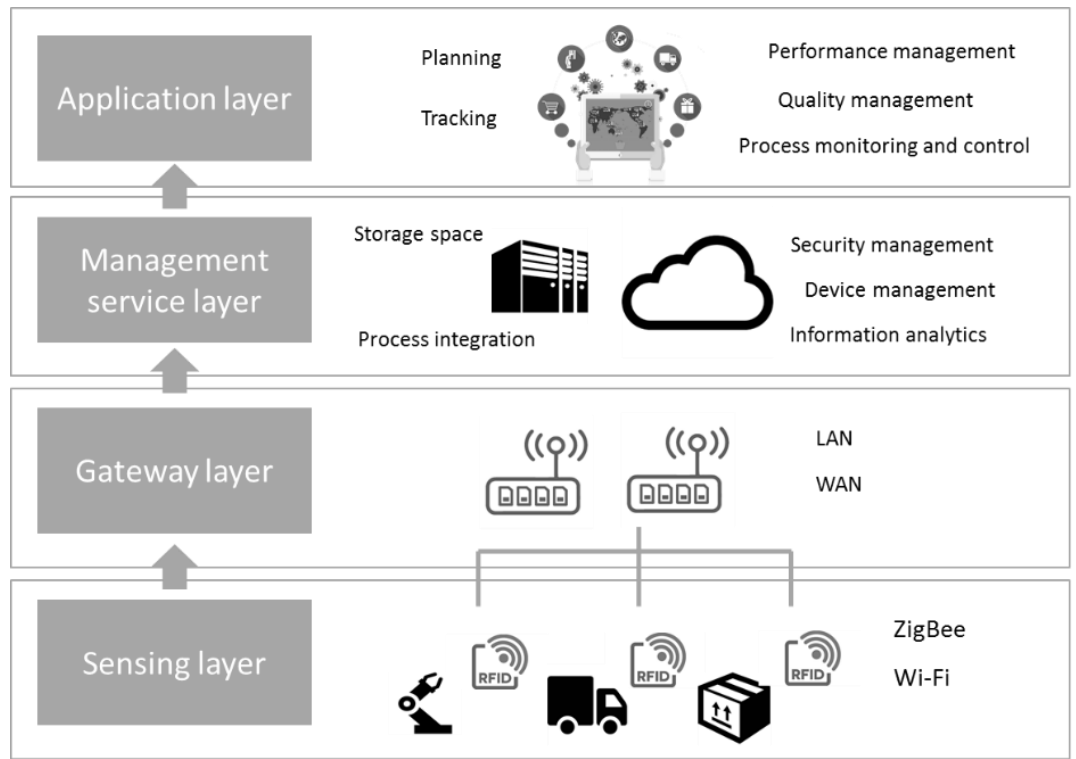

Source: Authors based on Dweekat et al. (2017).

Similarly, Xu et al. (2014) and Ben-Daya et al. (2017) suggest that a typical IoT network includes four main essential layers: (i) a sensing layer that integrates different types of 'things' like RFID tags and sensors; (ii) a networking layer that supports information transfer through a wired or wireless network; (iii) a service layer that integrates services and applications through a middleware technology; and (iv) an interface layer to display information to the user and that allows interaction with the system. According to Anusha et al. (2017) this tier contains applications for activities such as environment monitoring, service management, information management, technical management and cloud services. In turn, according to Giménez and Lourenço (2008) and Lin (2014) the interface layer includes Material Requirements Planning (MRP), Enterprise Resource Planning (ERP), Advanced Planning and Optimization (APO), Warehouse Management Systems (WMS), Customer Service Management (CSM), e-Procurement and e- 
Fulfillment. These applications process data and provide information to make decisions in different SCM processes. For example, MRP facilitates planning, scheduling, and inventory control in manufacturing processes. WMS provides data to optimise operations in warehouses or distribution centres. CSM analyses customer data with the goal to improve customer service and assist in customer retention. ERP integrates data on several key aspects in SCM such as purchasing, inventory management, vendor management, sales, and financial planning.

\subsubsection{IoT impact on SCM}

In the field of SCM there is a large body of literature that discusses the impact of information and communication technologies (ICTs) on supply chain performance. This literature suggests that ICTs can improve supply chain connectivity, which refers to the collaborative electronic linkage of partners up and down the supply chain (Closs and Swink, 2005; Sanders et al., 2011; Calatayud et al., 2016). In turn, connectivity is the critical enabler of supply chain visibility, allowing for the removal of technological barriers among supply chain members and the more effective management of supply chain operations (Golicic et al., 2002). Indeed, visibility is defined as the capability of sharing on-time and accurate data considered to be key or useful to operations, throughout the entire supply chain (Caridi et al., 2014; Nooraie and Parast, 2015; Somapa et al., 2018). Likewise, higher visibility leads to enhanced supply chain integration (Brusset, 2016; Gonul et al., 2017), defined as the coordination of operational, logistical, and planning data to improve production planning, inventory management, and distribution (Li et al., 2009). As stated by Sanders et al. (2011, p. 179), "the very foundations of the supply chain integration concept rest upon the assumption that collaboration takes place between supply chain partners, which is only made possible through bidirectional flows of voluminous rich information, including operations and planning data”.

With increased connectivity, visibility and integration, better supply chain performance can be achieved (Fawcett et al., 2007; Nooraie and Parast, 2015; Somapa et al., 2018). Literature on supply chain integration suggests that the higher the degree of integration among partners across the supply chain, the better a firm performs (Frohlich and Westbrook, 2001; Song and Panayides, 2008), and that the presence of information technologies and information connectivity is crucial to facilitate integration across the supply chain (Gosain et al., 2004; Song and Panayides, 2008). Among the benefits of enhancing connectivity and visibility are better inventory control (Fawcett et al., 2007; Narasimhan and Kim, 2001); shorter order fulfilment lead times and product development cycles (Erhun and Tayur, 2003; Fawcett et al., 2007); better monitoring of customer behaviour (Fawcett et al., 2007); enhanced capacity to design, monitor, and implement logistics plans (Gunasekaran and Ngai, 2004); greater logistics flexibility and improved delivery and logistics assets performance (Closs and Swink, 2005; Gosain et al., 2004); and better risk management (Hiromoto et al., 2017).

As evidenced by these studies, the relationship between ICT and supply chain performance is indirect, since it is mediated by the capability of ICT to increase supply chain connectivity, visibility, and/or integration (Li et al., 2009). Wu et al. (2016) and Gonul et al. (2017) illustrate one way in which this mediated relationship works. Deploying ICTs such as RFID enables tracking and tracing of goods in a supply chain. Through a collaborative platform, such information can be shared among supply chain partners in real-time. Increased information-sharing along the supply chain - in other words, higher connectivity - fosters supply chain visibility, allowing in turn for continuous adjustments to reduce replenishment lead times, inventory levels, batch size, and by improving demand forecasting (Yu et al., 2010; Qrunfleh and Tarafdar, 2012; Wu et al., 2016).

Leveraging on these studies, recent literature on IoT has investigated the specific impact of this technology on supply chain performance. Gnimpieba et al. (2015) emphasize that before IoT, supply chain collaboration was not possible, since the identification, traceability and real-time tracking of goods 
in supply chains was limited in terms of data availability and systems interoperability. In turn, Ben-Daya et al. (2017) specified that what was lacking thus far was not the availability of information but rather the technologies for collecting and processing big data and sharing it with supply chain partners. With IoT, a large amount of information can be collected, transferred, stored and shared in real time. Importantly, supply chain partners can be immediately informed when an event of interest occurs. This information can be accessed through a variety of devices (tablet, mobile phone, notebook PC), enabling real-time operation monitoring and decision-making, especially regarding potential supply chain disruptions (delayed container, infrastructure congestion, etc.) (Ben-Daya et al., 2017). Indeed, automated, real-time object identification is the core value of IoT (Rezaei et al., 2017; Yan et al. 2017). The visibility and traceability enabled by IoT technologies can significantly boost supply chain performance (Gunasekaran et al., 2017; Dweekat et al., 2017; Haddud et al., 2017; Dunke et al., 2018). Specifically, with IoT each event can be immediately recognized and recorded; supply chain partners have access to all of the generated data; this data improves performance and risk monitoring and informs decision-making towards optimization; decisions are immediately available to all valid parties; and plans are updated and implemented based on the new decisions (Cui, 2015; Dweekat et al., 2017; Gonul et al., 2017; Rezaei et al., 2017). For example, Dweekat et al., showed that the use of IoT in dairy supply chains reduced expiry waste percentage between $45 \%$ and $75 \%$ in milk retailing. This was possible because the expiry date for each product was monitored daily, it was visible to all supply chain members, and it improved distribution and demand forecasting with actual daily real-time information, instead of depending merely on the forecasted values using historical data. In turn, Hofmann (2017) showed that the speed of data transmission among supply chain partners had the greatest potential to enhance performance by significantly improving inventory management, if compared to data volume and variety. Therefore, the author suggested that in order to increase the potential benefit of IoT on SCM, data needed to be captured, processed and transferred as fast as possible.

Empirical evidence on the impact of IoT on SCM is growing. For the most part, studies focus on the use of RFID technology in different processes, nodes, and types of supply chains. This is due to the fact that RFID has been applied in the field of supply chain for several years now. Evidence can be found, for example, in Delen et al. (2007), Sarac et al. (2010), Lozano-Nieto (2012); Reaidy et al. (2015), Yan (2017), Yan et al. (2017), and Gu (2018). Most of the studies conclude that the information made available through the adoption of RFID technology in a supply chain is critical to improve supply chain operations, through increased visibility and integration between participants. Indeed, the key value from RFID lies not in the technology itself, but on the use supply chain actors make of the information generated. According to Moradpour and Bhuptani (2005), the real value of these data is in leveraging the information to monitor operations performance, discover patterns, ask new questions and make better business decisions.

However, it is erroneous to assume that generating data is all that matters to improve supply chain performance (Wu et al., 2017). Instead, data needs to be effectively managed, analysed and fed into models and computer programs to help the decision-making processes (Ben-Daya et al., 2017; Fore et al. 2017). IoT can provide data for two types of decision-making in supply chains: manned or automated (Wu et al., 2017). Most of the literature retrieved refers to decisions made by humans to improve supply chain performance (Haddud et al., 2017). However, IoT may also allow machine-enabled decision making with minimum or no human intervention (Zhou et al., 2015). Zjim and Klumpp (2015) suggest that the use of IoT to feed intelligent, automated systems will create a revolution in supply chain management. Similarly, Hofmann and Rusch (2017) propose that the digital dimension of the supply chain - where IoT generated data will be collected across the entire physical end-to-end supply chain will provide the critical information for autonomous and self-controlled systems to operate. Finally, $\mathrm{Lu}$ (2017) suggests that an IoT system, together with self-optimization and autonomous decision-making mechanism, will increase machine and equipment productivity. 
In spite of these potential gains outlined in the literature, studies on the relationship between IoT and autonomous supply chain decision making are still scarce. The search performed showed that there were only 22 articles combining IoT with autonomous decision making in SCM. Interestingly, 90\% of these studies are conference papers presented between 2016 and 2018, evidencing the novelty and the incipient nature of this area. Among them, 64\% belonged to the field of Computer Science, $45 \%$ to Engineering, and $32 \%$ to Business and Management (papers could belong to more than one field). Authors' affiliations were mainly located in China, Australia, and the United Kingdom. Among the limited number of articles available, particularly relevant to this study is the work of Wu et al. (2017), which explores the combination of different technologies to conceptualize the 'smart supply chain'. Such a supply chain is characterized by its high degree of cyber-physical interconnection through the use of IoT, which provides data for intelligent, large-scale decisions to optimize performance. In a smart supply chain, most of the processes are automated. Objects can sense the environment and respond to it. Therefore, human intervention is kept to a minimum. Similarly, Rezaei et al. (2017) propose a model for supply chain performance monitoring in which IoT-generated data feeds decision-making at both the strategic level, performed by human intelligence, and the operational level, which is performed by machine intelligence. While these studies provide a general analysis of and an estimation on how new digital technologies will impact SCM, the majority of the articles identified in our systematic literature review focus on either a specific subject in SCM or a specific type of supply chain. For example, Hiromoto et al. (2017) focus on the use of IoT and AI to develop a cyber-secure supply chain risk management architecture. Bogataj et al. (2017), and Lu and Wang (2017) suggest that IoT and AI can be used to enhance quality monitoring and improve decision making in perishable supply chains. Kusiak (2017) discusses the implementation of such technologies in smart manufacturing and the emergence of Industry 4.0. However, to our knowledge, there is currently no comprehensive study in the academic literature on the combined application of IoT and $\mathrm{AI}$ in SCM.

\subsection{Artificial intelligence and SCM}

Together with IoT, AI is the technology most often mentioned in practitioner research as the enabler of the autonomous, predictive supply chain (IBM, 2015; WEF, 2017). It is suggested that, in the near future, a variety of algorithms will be used to continuously monitor supply chain performance by analysing quintillion bytes of data generated by objects; forecast and identify risks; and automatically take actions to prevent risks before they materialize (Calatayud, 2017). Together with the large amounts of data generated by IoT, the use of powerful analytical and simulation models will allow the supply chain to predict the future with minimum error and take actions to address any deviation from expected performance (DHL, 2016). Regarding academic literature, the extensive database query we performed resulted, however, in very few articles specifically referring to AI and supply chains. Similar to the case of IoT, most of the studies retrieved were conference papers, evidencing the recent interest and application of these technologies to SCM. Indeed, while AI emerged in the 1950's as the science and engineering of making intelligent machines, advances in computer science have only recently made it possible to explore the potential of AI technology (Tatnall and Davey, 2017). Most of the studies retrieved belong to the fields of Computer Science (82\%) and $75 \%$ of them were published in the last ten years. Regarding the geographical location of authors' affiliations, 35\% were in the United States, $18 \%$ in the United Kingdom and 13\% in China. It should be highlighted though that when we explored references cited in the studies retrieved, we found a large body of literature that studied the use of AI on specific supply chain processes or activities, such as transportation, predictive maintenance, and demand forecasting (Lee et al., 2011; Bogataj et al., 2017; Cozar et al., 2017; Hill and Bose, 2017; Klumpp, 2017; Yang et al., 2017). Nevertheless, only a handful of these papers refer to AI from a supply chain perspective. 
Indeed, Min (2015) shows that while AI has increased, its role in improving managerial decision-making processes, and subsequently enhancing supply chain efficiency by avoiding the sub-optimisation of problem solutions, is still marginal. While the author certainly makes a significant contribution in exploring the application of AI to different supply chain processes, the study focuses on one type of AI only: the genetic algorithm. The work of Yeh et al. (2016) makes a further contribution to the study of the potential of AI for supply chain global optimization by showing how AI can help reduce operating costs at the supply chain level and enhance customer satisfaction. Merlino and Sproge (2017) also look at AI from a supply chain perspective and suggest that the use of predictive technologies to model future scenarios will help improve the effectiveness of supply chain operations, while at the same time develop a deeper understanding of the interactions of the various drivers on supply chain performance. However, their work remains at the exploratory level, forecasting that while there is still a long way to go before autonomous transportation is more common, the advent of Industry 4.0 and Smart Factories all powered by AI and IoT "will make running a supply chain as easy as pushing buttons" (Merlino and Sproge, 2017, p. 310). Similarly, when discussing the level of AI implementation in supply chain decision-making, Zijm and Klumpp (2015) suggest that unmanned decisions are already being made at some levels in the supply chain such as transportation, where automated vehicles with GPS-based navigation systems decide the route to take while interacting with the environment. Aside from transportation, the authors forecast that in the future AI applications will lead to automated production systems that will agilely adjust to real-time demand information, as well as to automated logistics systems that will decide to switch supplier when receiving real-time information about supply shortages or disruptions. In spite of these predictions, none of the studies retrieved comprehensively analyses the potential of AI technology for the broader supply chain.

The majority of the papers identified through our systematic literature review focus on more specific aspects of AI applied to supply chains, allowing us to group them in three categories, namely those papers that apply AI to: (i) increase the capacity to accurately predict demand or maintenance; (ii) analyse the potential or the use of this technology in specific supply chains; and (iii) explore the types of AI techniques used in the literature to respond to supply chain optimization problems. These categories are discussed below.

\subsubsection{AI and prediction accuracy}

Demand forecasts are critical for efficient SCM since they provide firms with the advantage of planning and anticipating for future needs (Slimani et al., 2015). Given that any error in demand forecasting can create significant losses along the supply chain - as traditionally illustrated by the bullwhip effect research on the use of AI as a forecasting technique is growing. The articles retrieved through the systematic literature review show that, at the supply chain level, research is particularly focusing on testing the application of different AI algorithms to this field; comparing the effectiveness of AI algorithms in demand forecasting, and between AI and traditional techniques; and improving the accuracy of AI for demand forecasting under data constraints (Kochak and Sharma, 2015; Nikolopoulos et al., 2016; Singh and Challa, 2016; Slimani et al., 2016).

The other area where AI is being applied to increase prediction accuracy is asset maintenance. The purpose of this is to reduce and eliminate the number of failures occurring during product use as any breakdown of machine or equipment may lead to disruption for the supply chain (Lee et al., 2016). While there are a large number of studies in Computer Science that explore this topic and it would require a separate study to review them all, in this paper we include examples found in the SCM literature. Lee $e t$ al. (2016) study AI applications for classifying the likely failure pattern and estimate the machine condition for the faulty component. Susto et al. (2015) present a multiple classifier machine learning methodology for predictive maintenance that allows dynamic decision rules to be adopted for maintenance management, and that can be used with high-dimensional and censored data problems. Yang 
et al. (2017) develop a predictive model based on a Particle Filtering method to increase the accuracy in estimating time to failure, thus enabling 'just-in-time' asset maintenance.

\subsubsection{AI applied to specific supply chains}

Among the papers retrieved, some studied the use of AI in specific industries or supply chains. Farahani et al. (2016) surveyed the use of this and other digital technologies in the automotive supply chain. Finding that firms in the supply chain were not equipped properly to cope with the opportunities and disruptions coming with those technologies, they provided a recipe for automotive supply chain managers on how to create a digital supply chain management agenda. Guo and Wong (2013), Wong et al. (2013) and Nayak and Padhye (2018) analysed the use of different types of AI - e.g. expert systems, neural networks, fuzzy logic, and genetic algorithm - in apparel supply chains, as a means to address operational challenges such as variable production volumes and high demand volatility. Abukhousa et al. (2014) and Santos et al. (2017) explored the application of AI in healthcare supply chains and suggested AI-based methods to optimize operations. Similarly, Dellino et al. (2017), Lu and Wang (2017) and Fikar (2018) proposed AI-based decision support systems to optimize processes in perishable supply chains. In the case of such supply chains, Lu and Wang (2017) combined IoT and AI technologies to enhance quality control of perishable food products in the cold chain industry. They provided an intelligent solution to ensure product traceability through IoT and they optimized complex logistics problems such as load planning and route planning with AI.

\subsubsection{AI techniques and supply chain optimization problems}

SCM problems are complex optimization problems. While a wide range of techniques have been applied to solve such problems, traditional mathematical methods have proven insufficient in accurately tackling them (Dounias and Vassiliadis, 2015). Due to recent progress in computer science, AI has emerged as a technology that promises to help overcome optimization problems in SCM. AI comprises nature-inspired algorithms such as Genetic Algorithms (GA), Fuzzy Systems, Neural Networks (NN), Ant Colony Optimization, Particle Swarm Optimization, Memetic Algorithms, Artificial Immune Systems, and DNA Computing (Vassiliadis and Dounias, 2009). Among these, GA are the most frequently applied to solve supply chain challenges (Icarte, 2016). The reason for this is that GA are mathematically less complex than other AI algorithms and they can handle different types of functions and constraints (Xu and Ding, 2011). The use of nature-inspired algorithms to solve specific supply chain challenges has been increasing in the last decade, particularly in distribution management, for example in the cases of the traveling salesman and vehicle routing problems (Mettler et al., 2012; Dounias and Vassiliadis, 2015). Other cases include inventory location, planning, and cost minimization, as well as supplier selection problems (Bintrup, 2010; Sinha et al., 2012; Ameri and McArthur, 2013; Kumar et al., 2013; Wang and Wang, 2015). Recent studies have used AI to solve multiple supply chain challenges at the same time. For example, Fikar (2018) developed an AI-based system aimed at reducing cost and food waste in perishable supply chains. For this, the AI-based system works simultaneously on optimizing both inventory management and delivery strategies. With the continuous growth of data availability on supply chain processes and the improvement of computational techniques, it is expected that AI will become one of the most critical technologies for SCM over the next few years (Merlino and Sproge, 2017).

\section{Towards the self-thinking supply chain}

Figure 3 illustrates our proposed model of a self-thinking supply chain set within its wider, information rich ecosystem. In the self-thinking supply chain there is a high degree of connectivity between cyber systems and physical objects through the use of IoT. Such IoT technology is ubiquitous through the deployment of sensors, short and long-range networks, and internet-enabled applications. Quintillions of 
data are generated, stored and analysed through IoT and AI in real time. This enables continuous monitoring of supply chain performance and early identification and management of potential risks. Increased connectivity among supply chain partners enabled by IoT, together with AI, allows for more accurate demand forecasting, predictive maintenance and continuous optimization. With AI, decisionmaking is machine-generated and processes are automated. Objects can sense the environment (through IoT) and respond to it according to AI-made decisions. Changes can be made at the micro level (e.g. at individual nodes in the supply chain) in order to optimise supply chain wide performance. Efficient, accurate, fast and simultaneously orchestrated responses can thus improve supply chain performance in an increasingly complex and uncertain world. Using real time data on both demand and available production and distribution capabilities the gearbox approach (Mangan and Lalwani, 2016, p. 179) (Figure 3 - Box B) can be used to regulate (speed up / slow down) the flow of materials downstream in the supply chain. For example, in the international clothing supply chain updates on congestion at port container terminals might lead to increased use of (more expensive but faster) air transport for the shipment of time sensitive fashion items. In practice, managers in such supply chains endeavour to optimise the air-sea distribution mix and self-thinking supply chain capabilities allow them to do this more accurately. Supply chain 'control towers' enabled by state of the art digital capabilities are now becoming a more common feature of many global supply chains.

Figure 3. The Self-thinking Supply Chain

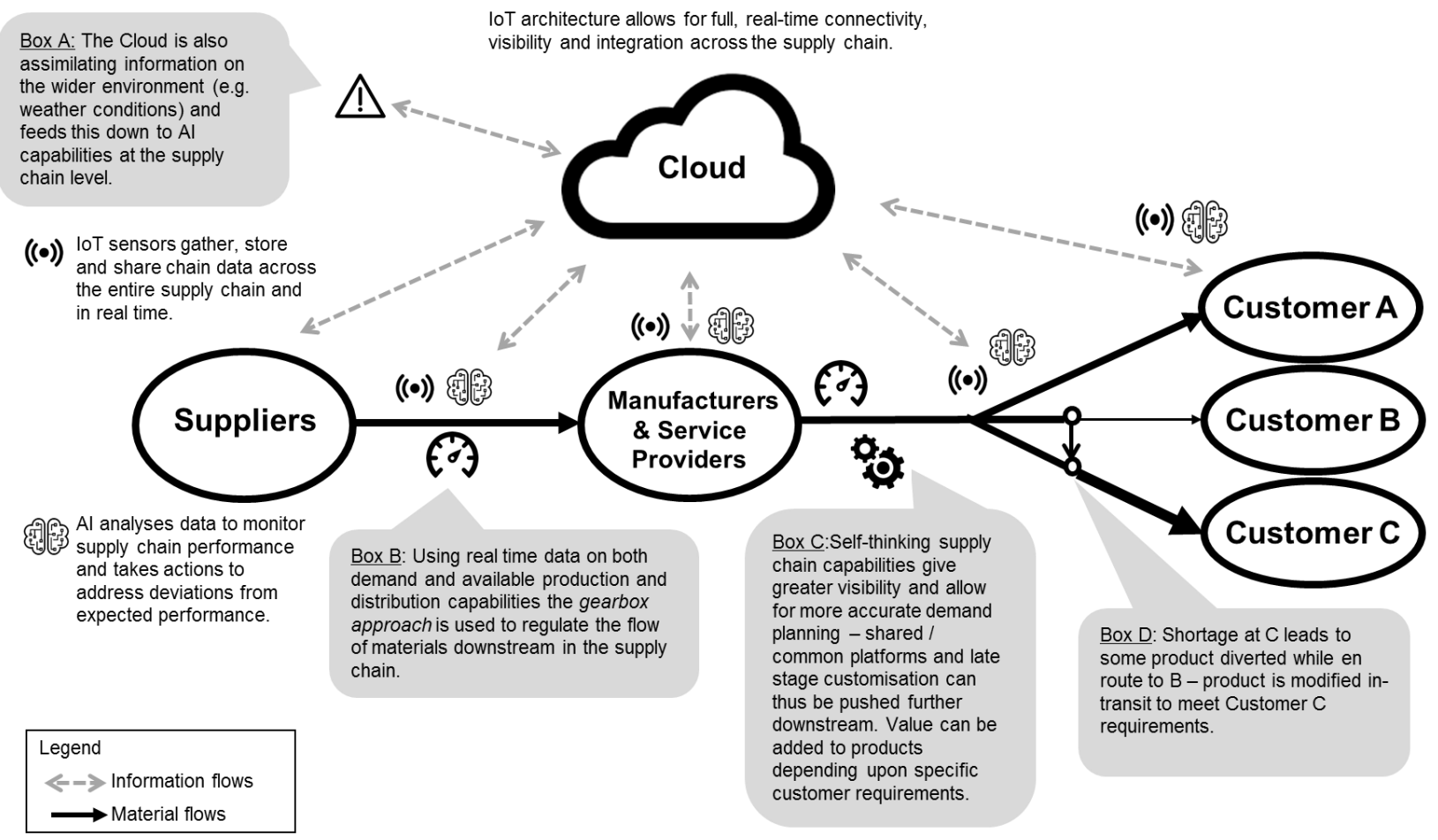

\subsection{The self-thinking supply chain can enhance agility}

One of the most commonly discussed - and desired - supply chain performance attributes is that of agility. More generally this capability allows supply chains to respond more quickly to market demand and is a key ingredient in the practice of mass customisation. There has been much discussion over the 
past circa 20 years on the role of agility in supply chain strategy. Christopher et al. (2006), building upon the work of Fisher (1997) and others, put forward a taxonomy for selecting global supply chain strategies and which uses both predictability of demand for products and replenishment lead times. Their taxonomy also incorporates lean and agile philosophies as appropriate; they argue that a 'one-size-fits-all' approach to supply chain strategy will not work and that companies need to continually assess their product range and market characteristics so that changing scenarios may be identified, and appropriate supply chain designs configured. This is the approach also taken by other authors such as Gattorna (2010) who argues for a dynamic capability in supply chain designs so that they can respond to any changes. He argues against designing supply chains for specific products because different types of demand can in fact exist for the same product, even among the same customer depending on when and why s/he wants to buy the product. Similarly, Christopher and Holweg (2011) have pointed to the need for structural flexibility and adaptability in supply chain design given the prevailing volatility and turbulence in the business environment. More recently Qamar and Hall (2018) investigated the distinctions between lean and agile organisations within the UK automotive sector. While there is ongoing debate around the correct sequencing of lean and agile capabilities / processes / supply chain nodes - there is nevertheless an emerging consensus in both the literature and in practice that (1) agile capabilities are a key pillar of many supply chains and (2) lean and agile approaches are not mutually exclusive. The self-thinking supply chain allows for greater agility, adaptability, flexibility and responsiveness through its ability to act quickly and autonomously. This is especially the case with supply chains dealing with products characterised by short lead times and unpredictable demand. Harvesting and analysis of data on inventory levels, demand requirements and performance of individual supply chain operations allows supply chains to be leaned as far as possible. The self-thinking supply chain thus facilitates the most judicious (optimised) mix of lean and agile supply chain strategies and practices to be pursued. It is notable that today many supply chains facilitate mass customisation - postponed production strategies allow late stage customisation, through a decoupling point, of final products downstream in the supply chain. Key in this regard is deciding where and when to do the final product customisation - and this is dependent upon both production capabilities (advances in same are discussed in the next sub-section) and (importantly) clarity of information on customer requirements. With its superior levels of data availability and analysis the self-thinking supply chain allows this decoupling point to be pushed further downstream towards the customer as there is now greater visibility and clarity around specific demand requirements (Figure 3 Box C).

The self-thinking supply chain can also improve supply chain risk management (SCRM). There is a growing awareness in recent years (Christopher and Holweg, 2011 and 2017; Simchi-Levi, 2014) of the impact of volatility and risk on supply chains. The sources of such risk are disparate and well documented. The key requirement is for supply chains now to be able to sense and respond accordingly a requirement facilitated by the many capabilities of the self-thinking supply chain and concomitant too with the aforementioned agile supply chain capabilities. In a self-thinking supply chain weather conditions could for example be continuously monitored in real time to assess demand for weather dependent merchandise - e.g. ice cream - thus minimising the risk of stock outs; similarly, the impact of weather on supply chain operations can be continuously monitored especially in the case of stretched supply chains with nodes in disparate locations (Figure 3 - Box A).

\subsection{The self-thinking supply chain can support additive manufacturing capabilities}

According to OECD (2016) a new production revolution is occurring because of a confluence of technologies - these include digital technologies, new materials, and new processes such as synthetic biology. The nature of products that are manufactured is changing, especially with developments in materials science and decarbonisation, with a shift evident too to lighter products with a higher value / volume ratio and lower transport cost sensitivity. Some products of course have been completely 
dematerialised (e.g. music CDs replaced by services such as Spotify); more widespread however is the trend towards servitisation (combining products and services). Aligned with the growth noted above in mass customisation is a shift in production capabilities driven in particular by the digital revolution. Direct digital manufacturing (DDM) allows manufacturers to produce parts directly from a CAD file thus eliminating timelags and investment in tooling, and lowering required production lot sizes (a shift then in focus from economies of scale to economies of scope). DDM takes advantage in particular of additive manufacturing technologies such as 3D and 4D printing (the latter embeds a transformation capability into the product - e.g. heating the product will alter its shape). Aligning this capability with mass customisation has heralded the era of the 'maker movement' where the consumer becomes part of product design and production (e.g. customers investing in their own 3D printers and 'manufacturing' on demand their required products). Consumers thus become 'prosumers' who both produce and consume their own products; this also cuts down on for example the need to carry spare parts and other products that may not be needed. Value add to products in transit may also become more common in the future e.g. 3D printing of products onboard ships that act as 'rolling warehouses' and 'floating factories'. This allows products to be customised closer to demand (Figure 3 - Box C). In Figure 3 (Box D) notice how material flows can change even when goods are in transit, and such changes may be both autonomous and predicated on analysis of real-time data (e.g. an author is announced as a major book prize winner in a particular country, instantly driving up demand for their book in that market - the supply chain may thus automatically divert product to that market without human intervention). Furthermore, the product itself may even change to comply with customer requirements; in a recent review of digitisation in the global logistics business, the Economist magazine (2018) for example gives an example of consignee labels being printed in transit as new orders arise (in the case of our book example this then might be labelling individual books, rendering them shelf ready, to accord with customer C's requirements); a (more radical) 4D printing illustration would for example be the addition of ingredients to an in-transit product and its further refinement (e.g. cooking) specific to a particular market's requirements. The (widely varying) predictions in both the literature and in the media concerning the future potential of 3D and 4D printing are outside the scope of this paper - suffice to note for now that the fascinating changes in production capabilities when combined with self-thinking supply chain capabilities have the potential when employed together to radically alter supply chain flows. ${ }^{[1]}$

\section{Conclusions}

Durach et al (2017, p. 76) suggest that "systematic literature reviews in SCM need to embrace findings that challenge the preconceived picture of the theoretical framework to thus stimulate the development of new or alternative explanations". In this paper we have put forward a new explanation, a new supply chain model - the self-thinking supply chain. The systematic literature review showed how the supply chain of the future - enabled by developments in ICT (especially IoT and AI) - will be autonomous and have predictive capabilities, bringing significant efficiency gains in an increasingly complex and uncertain environment. This self-thinking supply chain has the potential in particular to help address many of today's key supply chain challenges. We have shown that while it can contribute to the common supply chain strategies, it is especially apposite in the context of the growing demand for agility. The selfthinking supply chain concept may have a significant contribution to make especially in the context of poor and disadvantaged countries. Operating in such environments presents particular supply chain challenges (e.g. availability of logistics services, ability to track and trace freight). A key policy aim of international development organisations is to close the 'digital divide' and maximise digital dividends for all (World Bank, 2017). While not underestimating the challenges involved (both technical / infrastructure and regulatory) it is anticipated that in the context of the Fourth Industrial Revolution

\footnotetext{
${ }^{1}$ For more insights into the likely nature of future product flows see for example the work of the UK Government Office for Science Foresight projects - https://www.gov.uk/government/collections/foresight-projects
} 
information systems connectivity will increase at an exponential rate (Calatayud, 2017, p. 11) allowing poor and disadvantaged countries in particular to participate more fully in global supply chains. Once the digital divide among such countries is reduced they will be able to employ the various requisite selfthinking supply chain capabilities (e.g. use IoT sensors at ports to locate and thus speed up the flow of containers through their ports, thus enhancing port performance and in turn national logistics performance) and participate more fully and more efficiently in global trade. Indeed, it could be envisaged that such countries could quite quickly go from having few supply chain capabilities to having self-thinking supply chain capabilities. A particularly apposite analogy can be found in the telecoms sector: some developing countries had up until quite recently no telecoms infrastructure, however with the digital revolution rather than build fixed line telephone networks they jumped instead from having poor telephone networks to building state-of-the-art mobile communications networks, thus neatly jumping one stage of development!

Although there are limits to what can be included in any one paper, it is important to briefly consider the relevance of an emerging, exciting and most relevant (in the context of the self-thinking supply chain) technology viz. blockchain. It should be noted that very few publications retrieved through the systematic literature review focused on this technology (DHL, 2016; IBM, 2017). This is likely because this technology is at an early and nascent stage with relevant publications yet to emerge or perhaps still in press. Nevertheless, its potential to address supply chain challenges is very promising. This technology can help create and share information in an immediate, unalterable, and transparent fashion throughout the supply chain, without the need to set up costly centralized information-sharing systems. By using distributed ledger technology, all of the information shared in the network is stored in each node, making it easier to access and trace transaction history. Any change to the information stored in the distributed ledger must be approved by consensus by all the nodes in the network. Once the change is approved, the information is immediately stored in each node. This makes the system more resilient to failure or targeted attacks. In addition, since blockchain uses cryptography to guarantee the information stored in the distributed ledger, it makes it virtually impossible to alter the information already stored without having the consensus of the nodes in the network (ITF, 2018). This is an important feature to avoid forgery and fraud in the information shared, ensure materials provenance and allow for end-to-end product traceability. For example, together with the use of IoT, real-time sensor-generated information can be encrypted, validated, and shared among supply chain partners to ensure that the temperature, humidity, and quality conditions of materials and products have been unaltered in their flow thorough the supply chain (Kim and Laskowsky, 2016). Finally, the decentralized feature of blockchain eliminates the need for third parties to validate the information shared, which in turn reduces transaction costs and increases transparency (Iansity and Lakhani, 2017). In essence then blockchain capabilities complement and enhance self-thinking supply chain capabilities; combined together they have the potential, along too with the fascinating changes in production capabilities discussed above, to transform supply chain flows.

The self-thinking supply chain concept will help both practitioners to craft appropriate future-proofed supply chain strategies and provide the research community with a model (built upon multidisciplinary insights) for elucidating the application of new digital technologies in the supply chain of the future. Four immediate streams of further research in this regard can be envisaged viz (1) quantifying the benefits of such technology adoption (both specific individual technologies and combined technologies) for supply chain performance in different contexts (geographies, products) - the authors are currently progressing a project in this regard in the context of developing countries in Latin America, (2) designing and calibrating self-thinking supply chain architectures, again for different contexts, (3) investigating the risk of cyberthreats on the self-thinking supply chain, and (4) investigating - from both managerial and policy perspectives - how the self-thinking supply chain alters the locus of control and balance of power in the supply chain; does it give more control to the customer / consignee and / or conversely does the proliferation of data on all aspects of supply chain operations give rise to data privacy issues? (e.g. a customer doing an internet search on a new product discovers it is delivered to their home next day 
without an order having been placed but with an offer of a discount if they decide to buy it). The selfthinking supply chain heralds a new and exciting era in supply chain capability. As well as presenting an opportunity for economic and societal benefit, it also presents a fertile ground for further academic research.

\section{References}

Abukhousa, E., Al-Jaroodi, J., Lazarova-Molnar, S. and Mohamed, N. (2014), "Simulation and Modeling Efforts to Support Decision Making in Healthcare Supply Chain Management", The Scientific World Journal, Vol. 2014, pp. 1-16.

Ameri, F. and McArthur, C. (2013), "A multi-agent system for autonomous supply chain configuration", Int. J. Adv. Manuf. Technol., Vol. 66, pp. 1097-1112.

Anusha, M., Suresch, E., Sai, L., Vamsi, A. and Bhagiasree, B. (2017), "Performance analysis of data protocols of Internet of Things: a qualitative review", International Journal of Pure and Applied Mathematics, Vol. 115 No. 6, pp. 37-47.

Ben-Daya, M., Hassini, E. And Bahroun, Z. (2017), "Internet of things and supply chain management: a literature review", International Journal of Production Research, doi: 10.1080/00207543.2017.1402140.

Bintrup, A. (2010), "Behaviour adaptation in the multi-agent, multi-objective and multi-role supply chain", Computers in Industry, Vol. 61 No. 7, pp. 636-645.

Calatayud, A., Palacin, R., Mangan, J., Jackson, E. and Ruiz-Rua, A. (2016), "Understanding connectivity to international markets: a systematic review”, Transport Reviews, Vol. 36 No. 6, pp. 713-736.

Bogataj, D., Bogataj, M. and Hudoklin, D. (2017), "Mitigating risks of perishable products in the cyberphysical systems based on the extended MRP model", International Journal of Production Economics, Vol. 193, pp. 51-62.

Bowles, M. and Lu, J. (2014), "Removing the blinders: A literature review on the potential of nanoscale technologies for the management of supply chains", Technological Forecasting and Social Change, Vol. 82, pp. 190-198.

Brusset, X. (2016), “Does supply chain visibility enhance agility?", Int. J. Production Economics, Vol. 171, pp. 46-59.

Butner, K. (2010), "The smarter supply chain of the future”, Strategy and Leadership, Vol. 38 No. 1, pp. $22-31$

Calatayud, A. (2017), "The Connected Supply Chain: Enhancing Risk Management in a Changing World”, Discussion Paper No. 508, Inter-American Development Bank, Washington D.C.

Capgemini (2016), "The Current and Future State of Digital Supply Chain Transformation", available at: http://mktforms.gtnexus.com/rs/979-MCL-531/images/GTNexus-Digital-Transformation-Report-USFINAL.pdf (accessed 28 March 2018).

Caridi, M., Moretto, A., Perego, A. And Tumino, A. (2014), The benefits of supply chain visibility: A value assessment model, Int. J. Production Economics, Vol. 151, pp. 1-19.

Christopher, M. and Holweg, M. (2011), "Supply Chain 2.0: Managing Supply Chains in the Era of Turbulence", International Journal of Physical Distribution \& Logistics Management, Vol. 41 No. 1, pp. 63-82. 
Christopher, M. and Holweg, M. (2017), "Supply Chain 2.0 Revisited: A Framework for Managing Volatility-induced Risk in the Supply Chain”, International Journal of Physical Distribution \& Logistics Management, Vol. 47 No. 1, pp. 2-17.

Christopher, M., Peck, H. and Towill, D. (2006), “A taxonomy for selecting global supply chain strategies”, The International Journal of Logistics Management, Vol. 17 No. 2, pp. 277-287.

Cisco (2011), "The Internet of Things: How the Next Evolution of the Internet Is Changing Everything", White Paper, Cisco.

Closs, D. and Swink, M. (2005), "The role of information connectivity in making flexible logistics programs successful” International Journal of Physical Distribution and Logistics Management, Vol. 35, pp. 259-277.

Collins, J., Ketter, W. and Sadeh, N. (2010), "Pushing the Limits of Rational Agents: The Trading Agent Competition for Supply Chain Management”, AI Magazine, Vol. 31 No. 2, pp. 63-80.

Cozar, J., Puerta, J.M. and Gamez, J.A. (2017), “An application of dynamic Bayesian networks to condition monitoring and fault prediction in a sensored system: A case study", International Journal of Computational Intelligence Systems, Vol. 10 No. 1, pp. 176-195.

Cui, Y. (2015), "Improving supply chain resilience with employment of IoT", International Conference on Multidisciplinary Social Networks Research, pp. 404-414.

Delen, D., Hardgrave, B. and Sharda, R. (2007), "RFID for Better Supply-Chain Management through Enhanced Information Visibility", Production and Operations Management, Vol. 16 No. 5, pp. 613-624.

Dellino, G., Laudadio, T., Mari, R., Mastronardi, N. and Meloni, C. (2017), “A reliable decision support system for fresh food supply chain management", International Journal of Production Research, pp. 128.

Denyer, D. and Tranfield, D. (2009), "Producing a systematic review", in Buchanan D. and Bryman, A. (Eds.), The SAGE handbook of organizational research methods, Sage Publications Ltd., London, pp. 671-689.

Durach, C., Kembro, J. and Wieland, A. (2017), "A new paradigm for systematic literature reviews in supply chain management”, Journal of Supply Chain Management, Vol. 53, No. 4, pp. 67-85.

DHL (2015), "Internet of Things in Logistics", DHL, Germany.

DHL (2016), "Logistics Trend Radar", available at:

http://www.dhl.com/content/dam/downloads/g0/about us/logistics insights/dhl logistics trend radar 20 16.pdf (accessed 28 March 2018).

Dounias, G. and Vassiliadis, V. (2015), "Algorithms and methods inspired from nature for solving supply chain and logistics optimization problems: A survey", Research Methods: Concepts, Methodologies, Tools, and Applications, pp. 245-276.

Dunke, F., Heckmann, I., Nickel, S. and Saldanha-da-Gama, F. (2018), "Time traps in supply chains: Is optimal good enough?”, European Journal of Operational Research, Vol. 264, pp. 813-829.

Dweekat, A., Hwang, G. and Park, J. (2017), "A supply chain performance measurement approach using the internet of things: Toward more practical SCPMS", Industrial Management \& Data Systems, Vol. 117 No. 2, pp. 267-286.

Erhun, F. and Tayur, S. (2003), "Enterprise-Wide Optimization of Total Landed Cost at a Grocery Retailer", Operations Research, Vol. 51, pp. 343-353. 
Farahani, P., Meier, C. and Wilke, J. (2016), "Digital supply chain management agenda for the automotive supplier industry", Shaping the Digital Enterprise: Trends and Use Cases in Digital Innovation and Transformation, pp. 157-172.

Fawcett, S., Osterhaus, P., Mangan, G., Brau, J. and McCarter, M. (2007), "Information sharing and supply chain performance: the role of connectivity and willingness", Supply Chain Management: an International Journal, Vol. 12, pp. 358-368

Fikar, C. (2018), "A decision support system to investigate food losses in e-grocery deliveries", Computers and Industrial Engineering, Vol. 117, pp. 282-290.

Fisher, M. (1997), "What is the right supply chain for your product?", Harvard Business Review, MarchApril.

Fore, V., Khanna, A., Tomar, R. and Mishra, A. (2017), "Intelligent supply management system", in Proceedings of the 3rd International Conference on Advances in Computing, Communication and Engineering, pp. 296-302.

Frohlich. J. and Westbrook, L (2001), "Arcs of integration: an international study of supply chain strategies”, Journal of Operations Management, Vol. 19, pp. 185-200.

Gattorna, J. (2010), Dynamic Supply Chains (2nd edition), Financial Times/Prentice Hall, London.

Gimenez, C. and Lourenco, H. (2008), "e-SCM: internet's impact on supply chain processes", The International Journal of Logistics Management, Vol. 19 No. 3, pp.309-343.

Gligor, D. and Holcomb, M. (2012), "Antecedents and Consequences of Supply Chain Agility: Establishing the Link to Firm Performance", Journal of Business Logistics, Vol. 33, pp. 295-308.

Gnimpieba, D., Nait-Sidi-Moha, A. Durandb, D. and Fortina, J. (2015), "Using Internet of Things technologies for a collaborative supply chain: Application to tracking of pallets and containers", Procedia Computer Science, Vol. 56, pp. 550-557.

Golicic, S., Davis, D., McCarthy, T. and Mentzer, J. (2002), "The impact of e-commerce on supply chain relationships", International Journal of Physical Distribution \& Logistics Management, Vol. 32, pp. 851871.

Gonul, C., Nowicki, D.R., Sauser, B. and Randall, W.S. (2017), "Impact of cloud-based information sharing on hospital supply chain performance: A system dynamics framework", International Journal of Production Economics, doi: 10.1016/j.ijpe.2017.10.008.

Gosain, S., Malhotra, A. and El Sawy, O. (2004), "Coordinating for flexibility in e-business supply chains", Journal of Management Information Systems, Vol. 21, pp. 7-45.

Gu, C. (2018), "Fast Discrepancy Identification for RFID-Enabled IoT Networks", IEEE Access, Vol. 6, pp. 6194-6204.

Gunasekaran, A. and Ngai, E.W.T (2004), "Information systems in supply chain integration and management”, European Journal of Operational Research, Vol. 159, pp. 269-295.

Gunasekaran, A., Papadopoulos, T., Dubey, R., Wamba, S., Childe, S., Hazen, B. and Akter, S. (2017), "Big data and predictive analytics for supply chain and organizational performance", Journal of Business Research, January, pp. 308-317.

Guo, Z.X. and Wong, W.K. (2013), "Fundamentals of artificial intelligence techniques for apparel management applications", Optimizing Decision Making in the Apparel Supply Chain Using Artificial Intelligence (AI): From Production to Retail, pp. 13-40. 
Haddud, A., DeSouza, A., Khare, A. and Lee, H. (2017), "Examining potential benefits and challenges associated with the Internet of Things integration in supply chains", Journal of Manufacturing Technology Management, Vol. 28 No. 8, pp. 1055-1085.

Hill, A. and Bose, J.W. (2017), "A decision support system for improved resource planning and truck routing at logistic nodes", Information Technology and Management, Vol. 18 No. 3, pp. 241-251

Hiromoto, R., Haney, M. and Vakanski, A. (2017), "A secure architecture for IoT with supply chain risk management", 9th IEEE International Conference on Intelligent Data Acquisition and Advanced Computing Systems, Bucharest, September.

Hofmann, E. (2017), "Big data and supply chain decisions: the impact of volume, variety and velocity properties on the bullwhip effect", International Journal of Production Research, Vol. 55 No. 17, pp. 5108-5126.

Hofmann, E. and Rusch, M. (2017), "Industry 4.0 and the current status as well as future prospects on logistics", Computers in Industry, No. 89, pp. 23-34.

Iansiti, M. and Lakhani, K. (2017), "The Truth about Blockchain”, Harvard Business Review, Vol. 95 No. 1, pp. 118-127.

Icarte, G. (2016), "Applications of artificial intelligence in supply chain process: A systematic review", Ingeniare, Vol. 24 No. 4, pp. 663-679

IBM (2015), "The Smarter Supply Chain of the Future", available at: http://www03.ibm.com/innovation/us/smarterplanet/assets/smarterBusiness/supply_chain/GBE03215USEN.PDF (accessed 28 March 2018).

IBM (2017), “Top Supply Chain Trends for 2017”, available at: https://www01.ibm.com/common/ssi/cgi-bin/ssialias?htmlfid=ZZL03134USEN (accessed 28 March 2018).

ITF (2018), "Blockchain and Beyond: Encoding $21^{\text {st }}$ Century Transport", available at: https://www.itfoecd.org/blockchain-and-beyond (accessed 10 July 2018).

Jiang, Y. and Hao, S. (2011), "Research on the development of intelligent logistics based on internet of things", International Conference on Remote Sensing, Environment and Transportation Engineering, Nanjing, China.

Kim, H. and Laskowski, M. (2016), "Towards an Ontology-Driven Blockchain: Design for Supply Chain Provenance", available at: https://arxiv.org/abs/1610.02922v1 (accessed 18 March 2017).

Klumpp, M. (2017), “Automation and Artificial Intelligence in Business Logistics Systems: Human Reactions and Collaboration Requirements", International Journal of Logistics Research and Application, pp. 1-19

Kochak, A. and Sharma, S. (2015), "Demand forecasting using neural network for supply chain management”, Int. J. Mech. Eng. \& Rob. Res., Vol. 4 No. 1., pp. 96-104.

Kumar, A., Mukherjee, K. and Kumar, N. (2013), "A decision support system for control mechanism of inventory in a dynamic supply chain system considering supply-price trade-off using control theory", Int. J. of Business Performance and Supply Chain Modelling, Vol.5 No.3, pp.308-324.

Kusiak, A. (2017), “Smart manufacturing”, International Journal of Production Research, pp. 1-10. doi: 10.1080/00207543.2017.1351644

Lee, C.K.M., Cao, Y. and Ng, K.K.H. (2016), "Big data analytics for predictive maintenance strategies", Supply Chain Management in the Big Data Era, pp. 50-74. 
Lee, C.K.M., Ho, W., Ho, G.T.S. and Lau, H.C.W (2011), "Design and development of logistics workflow systems for demand management with RFID", Expert Systems with Applications, Vol. 38 No. 5, pp. 5428-5437.

Lee, H. and Ozer, O. (2007), "Unlocking the Value of RFID”, Production and Operations Management, Vol. 16 No. 1, pp. 40-64.

Li, G., Yang, H., Sun, L. and Sohal, A. (2009), "The impact of IT implementation on supply chain integration and performance”, Int. J. Production Economics, Vol. 120. No. 1, pp. 125-138.

Li, Y. (2008), "Adaptive multi-agent modeling in intelligent supply chain management", International Colloquium on Computing, Communication, Control, and Management, Guangzhou, China.

Liang, Y. and Li, L. (2007), "Integration of intelligent supply chain management (SCM) system", International Conference on Service Systems and Service Management, Chengdu, China.

Lopez, A., Veeke, H. and Lodewijks, G. (2007), "Intelligent supply chain by using prognostic logistics", International Journal of Services Operations and Informatics, Vol. 2 No. 2, pp.152-163.

Lozano-Nieto, A. (2012), "Radio frequency identification in the smart supply chain", in Eyob, E. and Tetteh, E., Customer-Oriented Global Supply Chains: Concepts for Effective Management, pp. 198-207.

Lu, Y. (2017), "Industry 4.0: A survey on technologies, applications and open research issues", Journal of Industrial Information Integration, Vol. 6, pp. 1-10.

Lu, S. and Wang, X. (2017), "Toward an intelligent solution for perishable food cold chain management", Proceedings of the IEEE International Conference on Software Engineering and Service Sciences, pp. 852-856.

Luckett, D. (2004), The Supply Chain, BT Technology Journal, Volume 22 No. 3, pp. 50-55.

Lumsden, K and Stefansson, G. (2007), "Smart freight to enhance control of supply chains", International Journal of Logistics Systems and Management, Vol. 3 No. 3, pp. 315-329.

Mangan, J. and Lalwani, C. (2016), Global Logistics and Supply Chain Management, $3^{\text {rd }}$ ed, Wiley, UK.

Martinez-Sala, A., Egea-Lopez, E., Garcia-Sanchez, F. And Garcia-Haro, J. (2009), "Tracking of Returnable Packaging and Transport Units with active RFID in the grocery supply chain", Computers in Industry, Vol. 60 No. 3, pp. 161-171.

Merlino, M. and Sproge, I. (2017), “The Augmented Supply Chain”, Procedia Engineering, Vol. 178, pp. 308-318.

Mettler, T., Pinto, R. and Raber, D. (2012), "An Intelligent Supply Chain Design for Improving Delivery Reliability”, International Journal of Information Systems and Supply Chain Management, Vol. 5 No. 2, pp. 1-20.

Min, H. (2015), "Genetic algorithm for supply chain modelling: Basic concepts and applications", International Journal of Services and Operations Management, Vol. 22 No. 2, pp. 143-164.

Narak, R. and Padhye, R. (2018), "Artificial intelligence and its application in the apparel industry", Automation in Garment Manufacturing, pp. 109-138.

Narasimhan, R. and Kim, S.W. (2001), "Information System Utilization Strategy for Supply Chain Integration”, Journal of Business Logistics, Vol. 22, pp. 51-75.

Nikolopoulos, K.I., Babai, M.Z. and Bozos, K. (2016), "Forecasting supply chain sporadic demand with nearest neighbor approaches", International Journal of Production Economics, Vol. 177, pp. 139-148.

Nooraie. S.V., and Parast, M. (2016), "A multi-objective approach to supply chain risk management: Integrating visibility with supply and demand risk", Int. J. Production Economics, Vol. 161, pp. 192-200. 
OECD (2016) Enabling the Next Production Revolution, available at: http://www.oecd.org/sti/ind/nextproduction-revolution.htm (accessed 15 July 2018).

Ounar, F., Pujo, P., Mekauche, L. and Giambiasi, N. (2007), "Customer-supplier relationship management in an intelligent supply chain network", Production Planning \& Control, Vol. 18 No. 5, pp. 377-387.

Papert, M. and Pflaum, A. (2017), "Development of an Ecosystem Model for the Realization of Internet of Things (IoT) Services in Supply Chain Management", Electron Markets, Vol. 27, pp. 175-189.

Qamar, A. and Hall. M. (2018), "Can lean and agile organisations within the UK automotive supply chain be distinguished based upon contextual factors?", Supply Chain Management: an International Journal, Vol. 23 No. 3, pp.239-254.

Qrunfleh, S. and Tarafdar, M. (2014), "Supply chain information systems strategy: Impacts on supply chain performance and firm performance”, Int. J. Production Economics, Vol. 147, pp. 340-350.

Resilinc (2018), "Resilinc study: 32\% of the S\&P 500 impacted in 2017", available at: https://www.resilinc.com/news/resilinc-study-32-sp-500-impacted-2017/ (accessed 28 March 2018).

Reaidy, P., Gunasekaran, A. and Spalanzani, A. (2015), "Bottom-up approach based on Internet of Things for order fulfillment in a collaborative warehousing environment", Int. J. Production Economics, Vol. 159 , pp. 29-40.

Rezaei, M., Shirazi, M. and Karimi, B. (2017), "IoT-based framework for performance measurement: A real-time supply chain decision alignment”, Industrial Management and Data Systems, Vol. 117 No. 4, pp.688-712.

Rousseau, D., Manning, J. and Denyer, D. (2008), "Evidence in management and organizational science: Assembling the field's full weight of scientific knowledge through syntheses", The Academy of Management Annals, Vol. 2, pp. 475-515.

Sanders, C., Autry, D. and Gligor, M. (2011), "The impact of buyer firm information connectivity: enablers on supplier firm performance", International Journal of Logistics Management, Vol. 22, pp. 179-201.

Santos, R.M., Orozco, J., Mosse, D., Petrucci, V., Ochoa, S.F. and Meseguer, R. (2017), "Flying RealTime Network for Disaster Assistance", in Ochoa, S., Singh, P. and Bravo, J. (eds.), Ubiquitous Computing and Ambient Intelligence, Vol. 10586, Springer, Cham.

Sarac, A., Absi, N. and Dauzere-Peres, S. (2010), "A literature review on the impact of RFID technologies on supply chain management", Int. J. Production Economics, Vol. 128, pp. 77-95.

Schwab, K. (2016), The Fourth Industrial Revolution, World Economic Forum, Geneva.

Simchi-Levi, D., Schmidt, W. and Wei, Y. (2014), "From superstorms to factory fires", Harvard Business Review, January-February.

Singh, L.P. and Challa, R.T. (2016), "Integrated Forecasting Using the Discrete Wavelet Theory and Artificial Intelligence Techniques to Reduce the Bullwhip Effect in a Supply Chain", Global Journal of Flexible Systems Management, Vol. 17 No. 2, pp. 157-169.

Sinha, A.K., Zhang, W.J. and Tiwari, M.K. (2012), "Co-evolutionary immuno-particle swarm optimization with penetrated hyper-mutation for distributed inventory replenishment", Engineering Applications of Artificial Intelligence, Vol. 25 No. 8, pp. 1628-1643.

Siurdyban, A. and Moller, C. (2012), "Towards intelligent supply chains: A unified framework for business process design", International Journal of Information Systems and Supply Chain Management, Vol. 5 No. 1, pp. 1-19. 
Slimani, I., El Farissi, I. and Achchab, S. (2015), "Application of game theory and neural network to study the behavioral probabilities in supply chain", Journal of Theoretical and Applied Information Technology, Vol. 82 No. 3, pp. 411-416.

Slimani, I., Farissi, I.E. and Al-Qualsadi, S.A. (2016), "Configuration of daily demand predicting system based on neural networks", Proceedings of the 3rd IEEE International Conference on Logistics Operations Management, art. no. 7731709.

Somapa, S., Cools, M. and Dullaert, W. (2018), "Characterizing supply chain visibility - a literature review", The International Journal of Logistics Management, doi: 10.1108/IJLM-06-2016-0150.

Song, D. and Panayides, P. (2008), "Global supply chain and port/terminal: integration and competitiveness", Maritime Policy \& Management, Vol. 35, 73-87.

Susto, G. A., Schirru, A., Pampuri, S., McLoone, S., and Beghi, A. (2015), "Machine Learning for Predictive Maintenance: A Multiple Classifiers Approach", IEEE Transactions on Industrial Informatics, Vol. 11 No. 3, pp. 812-820.

Tatnall, A. and Davey, B. (2017), "The internet of things and beyond: Rise of the non-human actors", The Internet of Things: Breakthroughs in Research and Practice, pp. 353-364.

The Economist (2018) "The global logistics business is going to be transformed by digitisation", print edition $-26^{\text {th }}$ April 2018.

Tranfield, D., Denyer, D., and Smart, P. (2003), “Toward a methodology for developing evidenceinformed management knowledge by means of systematic review", British Journal of Management, Vol. 14, pp. 207-222.

Vassiliadis, V. and Dounias, G. (2009), "Nature-Inspired Intelligence: A review of selected methods and applications", International Journal of Artificial Intelligence Tools, Vol. 18 No. 4, pp. 487-516.

Wang, S. and Notteboom, T. (2014), "The adoption of liquefied natural gas as a ship fuel: a systematic review of perspectives and challenges", Transport Reviews, Vol. 34, pp. 749-774.

Wang Y. and Wang D. (2015), "Multi-agent Based Intelligent Supply Chain Management", Proceedings of the Ninth International Conference on Management Science and Engineering Management, Vol. 362, pp. 305-312.

WEF - World Economic Forum (2017), "Impact of the Fourth Industrial Revolution on Supply Chains", available at:

http://www3.weforum.org/docs/WEF_Impact_of_the_Fourth_Industrial_Revolution_on_Supply_Chains_ .pdf (accessed 28 March 2018).

Wong, W.K., Guo, Z.X. and Leung, S.Y.S. (2013), Optimizing Decision Making in the Apparel Supply Chain Using Artificial Intelligence (AI): From Production to Retail, Woodhead Publishing, UK.

Wu, L., Yue, X., Jin, A. and Yen, D. (2016), "Smart supply chain management: a review and implications for future research", The International Journal of Logistics Management, Vol. 27 No. 2, pp. 395-417.

$\mathrm{Xu}, \mathrm{L} . \mathrm{D} ., \mathrm{He}, \mathrm{W}$. and Li, S. (2014), "Internet of Things in Industries: A Survey", IEEE Transactions on Industrial Informatics, Vol. 10 No. 4, pp. 2233-2243.

Yan, R. (2017), "Optimization approach for increasing revenue of perishable product supply chain with the Internet of Things", Industrial Management \& Data Systems, Vol. 117 Np. 4, pp.729-741.

Yan, B., Jin, Z., Liu, L. and Liu, S. (2017), "Factors influencing the adoption of the internet of things in supply chains", J. Evol. Econ., doi: 10.1007/s00191-017-0527-3.

Yang, X., Li, J., Pu, C., Yan, M., Sharafat, R.,Yang, J., Gakis, K. and Pardalos, P. (2017), "Traffic congestion and the lifetime of networks with moving nodes", Physical Review E, Vol. 95 No. 1, 012322. 
Yeh, W.-C., Lin, W.-T., Lai, C.-M., Lee, Y.-C., Chung, Y.Y. and Lin, J.-S. (2016), “Application of simplified swarm optimization algorithm in deteriorate supply chain network problem", IEEE Congress on Evolutionary Computation, pp. 2695-2700.

Yu, M., Ting, S. and Chen, M. (2010), "Evaluating the cross-efficiency of information sharing in supply chains", Expert Systems with Applications, Vol. 37, pp. 2891-2897.

Yuvaraj, S. and Sangeetha, M. (2016), "Smart supply chain management using internet of things(IoT) and low power wireless communication systems", Proceedings of the 2016 IEEE International Conference on Wireless Communications, Signal Processing and Networking, pp. 555-558.

Zhang, F.Z., He, H.X., Xiao, W.J. (2013), "Application analysis of Internet of Things on the management of supply chain and intelligent logistics", Applied Mechanics and Materials, Vol. 411-414, pp. 26552661.

Zhou, L., Chong, A. and Ngai, E. (2015), "Supply chain management in the era of the internet of things", Int. J. Production Economics, Vol. 159, pp. 1-3.

Zhu, X., Mukhopadhyay, S. and Kurata, H. (2012), "A review of RFID technology and its managerial applications in different industries", Journal of Engineering and Technology Management, Vol. 29 No. 1, pp152-167.

Zijm, H. and Klumpp, M. (2015), "Logistics and supply chain management: Developments and trends", Logistics and Supply Chain Innovation: Bridging the Gap between Theory and Practice, pp. 1-20. 